Nig. J. Biotech. Vol. 37(2): 13-21 (Dec. 2020)

ISSN: 01891731

Available online at

http://www.ajol.info/index.php/njb/index

and www.biotechsocietynigeria.org

DOI: https://dx.doi.org/10.4314/njb.v37i2.2

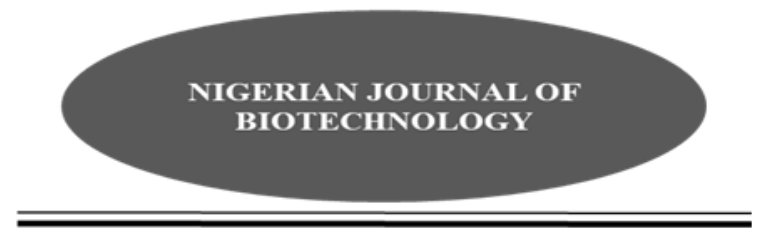

\title{
Optimisation of alkaline pretreatment conditions of orange and plantain peels for polygalacturonase production by Aspergillus awamori CICC 2040
}

\author{
Adedeji, O.E.. ${ }^{a, b *}$ and Ezekiel, 0.0. \\ aDepartment of Food Science and Technology, Federal University Wukari, PMB 1020, Wukari, Nigeria, \\ bDepartment of Food Technology, University of Ibadan, Ibadan, Nigeria.
}

\begin{abstract}
This study investigated the optimisation of alkaline pretreatment of orange and plantain peels for polygalacturonase (PG) production by Aspergillus awamori CICC 2040 using response surface methodology. The factors evaluated were particle size, PS $(<0.4250,0.4250<$ PS $<$ 0.8025 and $0.8025<\mathrm{PS}<1.1800 \mathrm{~mm}), \mathrm{NaOH}$ molarity $(0.010,0.055$, and $0.100 \mathrm{M})$, and time $(1.0,6.5$, and $12.0 \mathrm{~h})$. These factors were interacted to determine the most suitable combinations for maximum polygalacturonase activity (MPA). The pretreated orange and plantain peel powders were inoculated with $10^{6}$ spores $/ \mathrm{mL}$ Aspergillus awamori CICC 2040 was incubated at $28^{\circ} \mathrm{C}$ for 5 days, and crude PG was extracted and its activity determined. The alkaline pretreatment combinations that gave MPA were $<0.4250 \mathrm{~mm}, 0.100 \mathrm{M}$, and 1.0 $\mathrm{h}$, and $0.8025<\mathrm{PS}<1.1800 \mathrm{~mm}, 0.010 \mathrm{M}$, and $1.0 \mathrm{~h}$ for orange and plantain peel powders, respectively. The MPA obtained from the pretreated orange and plantain peel powders were 38.46 and $38.82 \mathrm{U} / \mathrm{mL}$, respectively. Optimised alkaline pretreatment conditions of the orange and plantain peels for MPA, produced by Aspergillus awamori CICC 2040, were established.
\end{abstract}

Keywords: $\quad$ Aspergillus awamori CICC 2040, Peel, Optimisation, Polygalacturonase, Pretreatment ${ }^{*}$ Corresponding author: adedeji@fuwukari.edu.ng

\section{Introduction}

Polygalacturonase (PG) (E.C. 3.2.1.15) is a pectinase involved in the degradation of polygalacturonan in plant's cell walls through the hydrolytic breakdown of glycosidic bonds that bind galacturonic acid moieties (Heerd et. al., 2012). Polygalacturonase is employed in food, paper and pulp, animal feed, waste management, and pharmaceutical industries (Tapre and Jain, 2014) and represents $10 \%$ of the estimated commercialised enzymes (Anuradha et. al., 2014). Polygalacturonase has been produced via solid-state fermentation (SSF) and submerged fermentation (SF) processes (Khatri et. al., 2015).
In recent times, there has been considerable interest in the use of food wastes and agricultural residues as substrates for the production of bio-products, both from the economic and environmental viewpoints. The utilisation of agricultural residues is increasing due to the high cost of traditional feedstocks (Wadhwa et. al., 2015). The environmental concerns of un-utilised wastes stem from the generation of hazardous materials that are released to nature as a result of their degradation. This results in environmental pollution, which has both short and long term effects (Obi et. al., 2016). Different pectin-rich agricultural by-products have been used as substrates for PG production (Ptichkina et. al., 2008; Anuradha et. al., 2010; Anuradha et. al., 
2014) and among these, orange and plantain peels have enjoyed high preferences due to their availability (Li et. al., 2015; Castillo-Isreal et. al., 2015).

The utilisation of agricultural residues and fruit processing wastes as substrates for microorganisms for the subsequent elaboration of bio-products are limited due to the high concentration of lignin, cellulose, and hemicelluloses, which are physical barriers that limit microbial and enzymatic hydrolysis of biomasses (Yu et. al., 2015). Specifically, lignin is known to adsorb enzymes, thereby reducing its degradation efficiency (Ju et. al., 2013). Cellulose has been considered a factor that limits the accessibility of microorganisms to agricultural residues. The severity of this occurrence is dependent on the residue's surface area, crystalline and amorphous ratio of cellulose as well as its degree of polymerisation (El-shishtawy et. al., 2015). Several studies have demonstrated that the bio-conversion rate of residues is dependent on the properties of cellulose (Li et. al., 2015; Yang et. al., 2017; Lai et. al., 2017).

The properties of enzymes, such as cellulase and xylanase, produced from pretreated agricultural by-products are well documented (Rahnama et. al., 2013; Salihu et. al., 2015). An increase in PG activity was reported for alkaline-pretreated highly lignocellulosic materials, such as wheat straw and palm leaves, by Trichoderma reesei under SSF (ElShishtawi et. al., 2015). The findings of Li et. al., (2015) also showed an increase in exopectinase activity of microwave-pretreated orange peels using Aspergillus japonicus under SF. However, information on the properties of PG produced by Aspergillus species using pretreated pectin-rich agricultural by-products under SSF is sparse. Furthermore, there is a paucity of information on the optimisation of pretreatment operation conditions of agricultural residues for improved PG production. Therefore, the objective of this study is to optimise the alkaline $(\mathrm{NaOH})$ pretreatment conditions of orange and plantain peels for maximum activity of PG, produced by Aspergillus awamoriCICC 2040, using response surface methodology.

\section{Materials and Methods}

\begin{abstract}
Materials
Peels of orange (Citrus sinensis L.) and plantain (Musa paradisiaca Linn.) were obtained from fruit and vegetable vendors at the premises of the University of Ibadan, Ibadan. The fungal strain, Aspergillus awamori CICC (China Centre of Industrial Culture Collection) 2040, was obtained from China National Research Institute of Food and Fermentation, Beijing, China. All reagents used were of analytical grade.
\end{abstract}

\section{Methods \\ Production of orange and plantain peel powders}

The orange and plantain peels were blanched $\left(80^{\circ} \mathrm{C}\right.$ for $\left.3 \mathrm{~min}\right)$, rinsed, and dried in a hot air oven (NL9023A, Genlab Ltd, Cheshire, England) at $60{ }^{\circ} \mathrm{C}$ for $48 \mathrm{~h}$. The dried peels were milled into powders and sieved into 3 different particle sizes with the aid of $0.4250,0.8025$, and $1.1800 \mathrm{~mm}$ sieves (United States Pharmacopoeia Standard Sieves). The powders were packaged in polyethylene containers (ZipLock, China) and stored at $-20{ }^{\circ} \mathrm{C}$ for subsequent analyses (Adedeji and Ezekiel, 2019).

\section{Alkaline pretreatment of orange and plantain peels}

The alkaline pretreatment method outlined by Salihu et. al. (2015) was adopted with little modification in the molarity of $\mathrm{NaOH}$. Substrate flours ( $5 \%$ w/v) were treated with $\mathrm{NaOH}$ (Loba Chemie, India) at varying pretreatment conditions. Pretreated samples were rinsed with distilled water to a $\mathrm{pH}$ value of 7, dried in a hot air oven (NL9023A, Genlab Ltd, Cheshire, England) at $60^{\circ} \mathrm{C}$ for $24 \mathrm{~h}$, and stored at -20 $\pm 2{ }^{\circ} \mathrm{C}$ for subsequent analyses.

\section{Experimental design for alkaline pretreatment variables of orange and plantain peels}

Face centered central composite design under the response surface methodology was used for the evaluation of three independent variables for alkaline pretreatment. The variables were particle size, PS $(<0.4250,0.4250<$ PS < 0.8025 , and $0.8025<\mathrm{PS}<1.1800 \mathrm{~mm}$ ), $\mathrm{NaOH}$ molarity $(0.010,0.055$, and $0.100 \mathrm{M})$ and pretreatment time $(1.0,6.5$, and $12.0 \mathrm{~h})$. The factors were interacted to determine the most 
suitable combinations for maximum polygalacturonase activity.

\section{Production of polygalacturonase Culturing of microorganism}

The fungal strain was maintained on malt extract agar (MEA) at $28{ }^{\circ} \mathrm{C}$ for 6 days. Inoculums for the experiments were prepared from heavily sporulated MEA slants (Adedeji and Ezekiel, 2019).

\section{Solid-state production of polygalacturonase}

The solid-state fermentation procedure described by Dey et al., (2014) was adopted. Orange peel powder (OPP) and plantain peel powder (PPP) were mixed with Czapek-dox medium (2.5 g/L NaNO $3,1 \mathrm{~g} / \mathrm{L} \mathrm{KH}_{2} \mathrm{PO}_{4}, 0.5 \mathrm{~g} / \mathrm{L}$ $\mathrm{KCl}$ and $0.5 \mathrm{~g} / \mathrm{L} \mathrm{MgSO}_{4} .2 \mathrm{H}_{2} \mathrm{O}$ ) at $\mathrm{pH} 4.0$ in ratio $1: 2(\mathrm{w} / \mathrm{v})$ in a $250 \mathrm{~mL}$ Erlenmeyer flask and autoclaved $\left(121{ }^{\circ} \mathrm{C}, 15 \mathrm{psi}\right)$ for $15 \mathrm{~min}$. Subsequently, the substrate was inoculated with $10^{6}$ spores $/ \mathrm{mL}$ of the culture and incubated in an incubator (CLN115, Pol Eko Aparatura, Slaski, Poland) at $28^{\circ} \mathrm{C}$ for 5 days. After this, the fermented mass was suspended in distilled water to form a $50 \mathrm{~g} / \mathrm{L}$ suspension. The suspension was placed in an incubator (CLN115, Pol Eko Aparatura, Slaski, Poland) at $30{ }^{\circ} \mathrm{C}$ for $1 \mathrm{~h}$ and centrifuged (K24IR, Centurion Scientific Ltd, Chichester, UK) at $2200 \times \mathrm{g}$ for 10 min. The supernatant was separated using Whatman No. 1 filter and PG assay conducted. The enzyme obtained was stored at $-20{ }^{\circ} \mathrm{C}$ until required.

\section{Determination of polygalacturonase activity}

The activity of PG was determined based on the procedure outlined by Dey et. al. (2014). A 0.5 $\mathrm{mL}$ each of $\mathrm{PG}$ and $0.5 \%$ polygalacturonic acid was prepared in acetate buffer $(\mathrm{pH} 5.0)$ and the mixture incubated in a water bath (NL42OS, Genlab Ltd, Cheshire, England) at $50{ }^{\circ} \mathrm{C}$ for 10 min. Thereafter, a $3 \mathrm{~mL}$ of freshly prepared 3 , 5 di-nitro salicylic acid solution was added and the mixture heated at $90{ }^{\circ} \mathrm{C}$ for $15 \mathrm{~min}$. The mixture was rapidly cooled and absorbance read at $575 \mathrm{~nm}$ with the aid of a UV/VIS spectrophotometer (Jenway 6850, ColeParmer, Staffordshire, UK). One unit of PG activity was calculated as the amount of enzyme required to release $1 \mu \mathrm{mol}$ of $D$ galacturonic acid per minute of reaction $(\mu \mathrm{mol} / \mathrm{min})$. A blank was prepared by mixing a buffer, DNS, and distilled water, and subjected to similar treatment as the enzyme solution. Polygalacturonase activity was expressed in unit of activity per $\mathrm{mL}(\mathrm{U} / \mathrm{mL})$.

\section{Statistical analyses}

The experiments were conducted in triplicates and means of the measured variables were used to generate the response (PG activity). A linear equation was fitted to the data by a multiple regression procedure (Equation 1).

$$
\begin{array}{cccc} 
& Y=\alpha_{0}+\sum_{i=1}^{n} & \alpha_{i} X_{i}+\sum_{i=1}^{n} & \alpha_{i i} X_{i}{ }^{2}+ \\
\sum_{i=1}^{n-1} & \sum_{i=1}^{n} & \alpha_{i j} X_{i} X_{j} &
\end{array}
$$

Where $Y$ represents predicted response, PG activity $(\mathrm{U} / \mathrm{mL}), \quad X_{1}, X_{2}, X_{3} \ldots \ldots . . . \mathrm{n}$ are independent variables, $a_{0}$ is a constant, and ai, aii, and aij are linear, squared and interaction effects, respectively. The multiple regression model was evaluated with the aid of analysis of variance (ANOVA) and the quality of fit was tested by determining the coefficient of correlation $\left(R^{2}\right)$. These were achieved using the Minitab software, version 16.2.1 (Stat-Ease Inc., Minneapolis, USA).

\section{Results and Discussion}

\section{Optimisation of alkaline pretreatment conditions of orange and plantain peels for maximum polygalacturonase activity}

The activity of the PG obtained at different combinations of alkaline pretreatment variables for OPP and PPP is presented in Table 1. Polygalacturonase activity ranged from 11.05 (Run 2) to $38.46 \mathrm{U} / \mathrm{mL}$ (Run 3), and 12.59 (Run 7) to $38.82 \mathrm{U} / \mathrm{mL}$ (Run 2) on OPP and PPP, respectively. For OPP, a maximum PG activity of $38.46 \mathrm{U} / \mathrm{mL}$ was obtained at Run 3 i.e. < $0.425 \mathrm{~mm}, 0.1 \mathrm{M} \mathrm{NaOH}$ and $1 \mathrm{~h}$. However, a maximum PG activity of $38.82 \mathrm{U} / \mathrm{mL}$ was obtained from Run 2 i.e. $0.8025<$ PS $<1.1800$ $\mathrm{mm}, 0.01 \mathrm{M}$, and $1 \mathrm{~h}$ for PPP. The difference in the chemical composition of the orange and plantain peels might have been responsible for the variation. According to Li et. al., (2015), chemical constituents, such as pectin and sugars, partly determine enzymatic activity. Earlier studies have also shown the differences in the activity of PG obtained from different substrates (Anuradha et. al., 2010; Padma et. al., 2012; Heerd et. al., 2014). The activity of 
PG varied significantly $(p<0.05)$ depending on the particle size of the peel powders, the molarity of $\mathrm{NaOH}$, and pretreatment time. The variation validated the need for optimisation of substrate pretreatment before enzyme production. The low PG activity recorded for Runs 2, 6, and 10 for OPP and 7 and 9 for PPP could be due to the low proliferation of Aspergillus awamori CICC 2040 under the prevailing conditions. The slow microbial growth that results from the unfavourable nutrient and non-nutrient based factors reduces the rate of metabolism and hence, the yield of the bioproducts (Akinpelu et. al., 2016). The experimental and predicted PG activity obtained at each pretreatment combination was significantly close. For example, the experimental and predicted PG activity obtained from OPP at Run 8 were 38.46 and $38.10 \mathrm{U} / \mathrm{mL}$, respectively. This is an indication of a high degree of positive correlation. This implied suitability of the response surface methodology in the analysis of pretreatment variables for improved PG activity.

The significance $(p<0.05)$ of each variable as assessed by ANOVA is presented in Table 2 . High F-value of 71.42 and 21.88 for PG activity produced using OPP and PPP, respectively, showed the significance of the model. This is corroborated by a very low $p$-value of 0.00 and non-significant $(p>0.05)$ lack of fit. $R^{2}$ and $R^{2}$ (adjusted) values of $98.47 \%$ and $97.09 \%$, respectively, for PG activity from pretreated OPP validated that the model was in good agreement with the experimental data. Also, $\mathrm{R}^{2}$ and $\mathrm{R}^{2}$ (adjusted) values of $95.17 \%$ and $90.82 \%$, respectively, showed good agreement of the model with PG activity obtained from pretreated PPP. The findings suggest the models covered $98.47 \%$ and $95.17 \%$ of the variations in the predicted and experimental data of the PG obtained from the pretreated OPP and PPP, respectively.

For the activity of PG produced from pretreated OPP, one term each of linear ( $X_{1}$ - particle size), quadratic $\left(\mathrm{X}_{1}{ }^{2}\right.$ - particle size $\times$ particle size $)$ and two cross-product combinations, $X_{1} X_{2}$ (particle size $\times \mathrm{NaOH}$ molarity), and $\mathrm{X}_{2} \mathrm{X}_{3}(\mathrm{NaOH}$ molarity $\times$ time) were found to be significant. Therefore, the remaining non-significant $(p>$ 0.05 ) terms were deleted from the regression equation (Equation 2).

$$
\begin{aligned}
& Y=43.47-1.34 X_{3}-20.47 X_{1}^{2}+81.83 X_{1} X_{2} \\
& 1.30 X_{1} X_{3}
\end{aligned}
$$

The significant $(p<0.05)$ terms for PG activity obtained from the pretreated PPP were $X_{3}, X_{3}{ }^{2}$, $\mathrm{X}_{1} \mathrm{X}_{2}$, and $\mathrm{X}_{2} \mathrm{X}_{3}$ (Equation 3).

$Y=15.31-0.80 X_{3}-0.09 X_{3}^{2}+87.42 X_{1} X_{2}+$
$7.38 X_{2} X_{3}$

Effect of alkaline pretreatment of orange and plantain peels on polygalacturonase activity

The alkaline pretreatment variables, substrate particle size, $\mathrm{NaOH}$ molarity, and pretreatment time, had a significant $(p<0.05)$ effect on PG activity. Figure $1 a$ and $b$ show the contour plots for the interactive effects of substrate particle size and molarity of $\mathrm{NaOH}$ on the PG activity obtained from OPP and PPP, respectively. The maximum PG activity was obtained at the lowest OPP's particle size $(<0.4250 \mathrm{~mm})$ and the highest $\mathrm{NaOH}$ molarity $(0.10 \mathrm{M})$ and vice versa. Maeda et. al., (2011) also reported an increase in the enzymatic hydrolysis of sugarcane bagasse pretreated with $1-4 \% \mathrm{NaOH}$ and a reduction at $\mathrm{NaOH}$ concentration of $0.5 \%$. The reduction in particle size increases substrates' surface area, which in turn increases the bioavailability of nutrients for microbial proliferation, hence, improved yield of bio-products (Salihu et. al., 2015). Low PG activity was obtained at low $\mathrm{NaOH}$ molarity probably due to the non-inhibition of chemical barriers at low $\mathrm{NaOH}$ concentration. For example, OPP is a rich source of limonene and essential oils, which are inhibitory to enzymatic hydrolysis (Li et. al., 2015; Wu et. al., 2017). However, the maximum PG activity was produced from PPP, with $0.8025<\mathrm{PS}<1.18 \mathrm{~mm}$ particle size, pretreated with $0.01 \mathrm{M} \mathrm{NaOH}$. This is advantageous because of the reduction in the $\mathrm{NaOH}$ consumption and the energy required for size reduction. Low et. al., (2015) also reported a reduction in the glucanase activity produced using banana pseudostem pre-treated with highly concentrated $\mathrm{NaOH}$. The low PG activity produced from PPP pretreated at the high molar concentration of $\mathrm{NaOH}$ could be due to the destruction of carbohydrates that might have resulted in the production of inhibitory compounds (Pandey and Negi, 2015). 
Table 1: The activity of polygalacturonase from Aspergillus awamori CICC 2040 on alkaline pretreated orange and plantain peels

\begin{tabular}{|c|c|c|c|c|c|c|c|}
\hline \multirow[b]{3}{*}{ Run } & \multirow{2}{*}{\multicolumn{3}{|c|}{$\underline{\text { Independent variables }}$}} & \multicolumn{4}{|c|}{ PG activity $(\mathrm{U} / \mathrm{mL})$} \\
\hline & & & & \multicolumn{2}{|c|}{ Orange peel powder } & \multicolumn{2}{|c|}{ Plantain peel powder } \\
\hline & Particle size (mm) & Molarity (M) & Time (h) & Experimental & Predicted & Experimental & Predicted \\
\hline 1 & $<0.4250$ & 0.010 & 1.0 & 35.23 & 36.82 & 21.97 & 23.57 \\
\hline 2 & $0.8025<P S<1.1800$ & 0.010 & 1.0 & 11.05 & 10.68 & 38.82 & 37.54 \\
\hline 3 & $<0.4250$ & 0.100 & 1.0 & 38.46 & 38.10 & 21.62 & 18.82 \\
\hline 4 & $0.8025<P S<1.1800$ & 0.100 & 1.0 & 16.73 & 17.52 & 36.73 & 38.73 \\
\hline 5 & $<0.4250$ & 0.010 & 12.0 & 30.05 & 29.36 & 28.74 & 26.90 \\
\hline 6 & $0.8025<P S<1.1800$ & 0.010 & 12.0 & 13.59 & 14.05 & 37.24 & 40.20 \\
\hline 7 & $<0.4250$ & 0.100 & 12.0 & 33.53 & 34.00 & 12.59 & 14.03 \\
\hline 8 & $0.8025<$ PS $<1.1800$ & 0.100 & 12.0 & 25.74 & 24.24 & 34.71 & 33.27 \\
\hline 9 & $<0.4250$ & 0.055 & 6.50 & 34.09 & 33.07 & 15.23 & 16.87 \\
\hline 10 & $0.8025<P S<1.1800$ & 0.055 & 6.50 & 14.50 & 15.12 & 35.68 & 33.44 \\
\hline 11 & $0.4250<$ PS $<0.8025$ & 0.010 & 6.50 & 26.47 & 25.48 & 31.40 & 29.96 \\
\hline 12 & $0.4250<P S<0.8025$ & 0.100 & 6.50 & 30.62 & 31.22 & 23.31 & 24.12 \\
\hline 13 & $0.4250<P S<0.8025$ & 0.055 & 1.00 & 29.01 & 27.36 & 28.74 & 29.22 \\
\hline 14 & $0.4250<P S<0.8025$ & 0.055 & 12.00 & 25.74 & 27.00 & 29.28 & 28.16 \\
\hline 15 & $0.4250<P S<0.8025$ & 0.055 & 6.50 & 26.35 & 27.02 & 25.75 & 25.87 \\
\hline 16 & $0.4250<$ PS $<0.8025$ & 0.055 & 6.50 & 26.11 & 27.02 & 25.50 & 25.87 \\
\hline 17 & $0.4250<$ PS $<0.8025$ & 0.055 & 6.50 & 26.78 & 27.02 & 25.61 & 25.87 \\
\hline 18 & $0.4250<$ PS $<0.8025$ & 0.055 & 6.50 & 27.01 & 27.02 & 25.89 & 25.87 \\
\hline 19 & $0.4250<$ PS $<0.8025$ & 0.055 & 6.50 & 27.57 & 27.02 & 25.90 & 25.87 \\
\hline 20 & $0.4250<\mathrm{PS}<0.8025$ & 0.055 & 6.50 & 27.50 & 27.02 & 25.29 & 25.87 \\
\hline
\end{tabular}


Adedeji and Ezekiel./ Nig. J. Biotech. Vol. 37 Num. 2 : 13-21 (Dec 2020)

Table 2: Analysis of variance of fitted models of polygalacturonase from alkaline pretreated orange and plantain peels

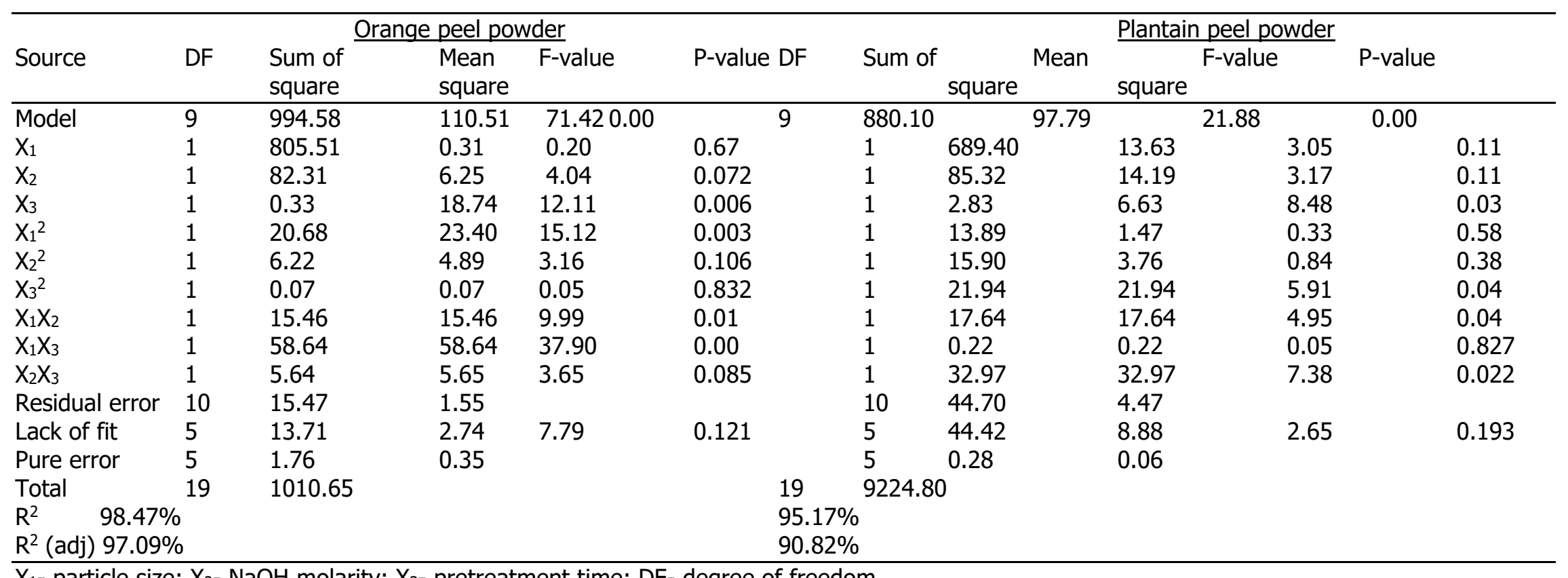


Figures $1 \mathrm{c}$ and $\mathrm{d}$ show the interactive effect of substrate particle size and pretreatment time on PG activity from pretreated OPP and PPP, respectively. The results show that the variables had a significant $(p<0.05)$ effect on PG activity. This corroborated the findings of Han et. al., (2012) who reported improved enzymatic hydrolysis of wheat straw following the synergistic effect of particle size and pretreatment time. Improved enzymatic activity is related to an increase in the adsorption of microorganisms on carbohydrate fibers, which is a consequence of surface area and time. The maximum PG activity was obtained from OPP with a particle size of $<0.42500 \mathrm{~mm}$ pretreated for $1 \mathrm{~h}$. Besides, PPP pretreated for $1 \mathrm{~h}$ gave the maximum PG activity, however, at a substrate particle size of $0.8025<$ PS $<1.1800$ $\mathrm{mm}$. The activity of PG decreased as the substrate pretreatment time increased. Figure 1e shows the effect of $\mathrm{NaOH}$ molarity and pretreatment time on the activity of PG produced on OPP. Pre-treatment time had no significant effect ( $p>0.05$ ) on PG activity produced from the OPP pretreated with $0.1 \mathrm{M} \mathrm{NaOH}$. The maximum PG activity ( $>32 \mathrm{U} / \mathrm{mL}$ ) was recorded at $0.1 \mathrm{M} \mathrm{NaOH}$ irrespective of pretreatment time. However, at a lower $\mathrm{NaOH}$ molarity, high pretreatment time ( $>4 \mathrm{~h}$ ) resulted in a reduction in PG activity. A reduction in enzymatic hydrolysis was also reported for wheat straw due to long $\left(>1 \frac{1}{2} h\right)$ alkaline pretreatment time. The reduction in PG activity at prolonged pretreatment time could be due to the destruction of inducer substrates, such as pectin and sugars, owing to the increased saponification rate of their ester bonds (Santos et. al., 2011). For the PG produced from PPP, the maximum PG activity was obtained at low $\mathrm{NaOH}$ molarity and high pretreatment time (Figure 1f). Sahare et. al., (2012) also reported maximum enzymatic hydrolysis for corncob subjected to prolonged (> $4 \mathrm{~h}$ ) alkaline pretreatment.

Model validation for alkaline pretreatment of orange and plantain peels

The adequacy of the regression equation was validated by conducting the experiment using the terms of the optimised conditions. The percentage deviation was 0.94 and $3.40 \%$ for OPP and PPP, respectively. Since the values were less than $5.0 \%$, it can be concluded, therefore, that the model was suitable for the description of the experiment (Ezekiel and Aworh, 2018).

\section{Conclusions}

This study established the alkaline pretreatment conditions of orange and plantain peels for maximum activity of PG produced by Aspergillus awamori CICC 2040. The alkaline pretreatment combinations that gave the maximum polygalacturonase activity were $<0.4250 \mathrm{~mm}, 0.100 \mathrm{M}$, and $1.0 \mathrm{~h}$ and $0.8025<$ $\mathrm{PS}<1.1800 \mathrm{~mm}, 0.010 \mathrm{M}$, and $1.0 \mathrm{~h}$ for orange and plantain peel powders, respectively. The maximum polygalacturonase activity obtained from pretreated orange and plantain peel powders were 38.46 and $38.82 \mathrm{U} / \mathrm{mL}$, respectively.

\section{Acknowledgement}

Special thanks go to the Tertiary Education Trust Fund of the Federal Republic of Nigeria for the Research Fellowship (FUW/REG/S.39/vol.1/024) granted to Adedeji, O.E. 
Adedeji and Ezekiel./ Nig. J. Biotech. Vol. 37 Num. 2 : 13-21 (Dec 2020)
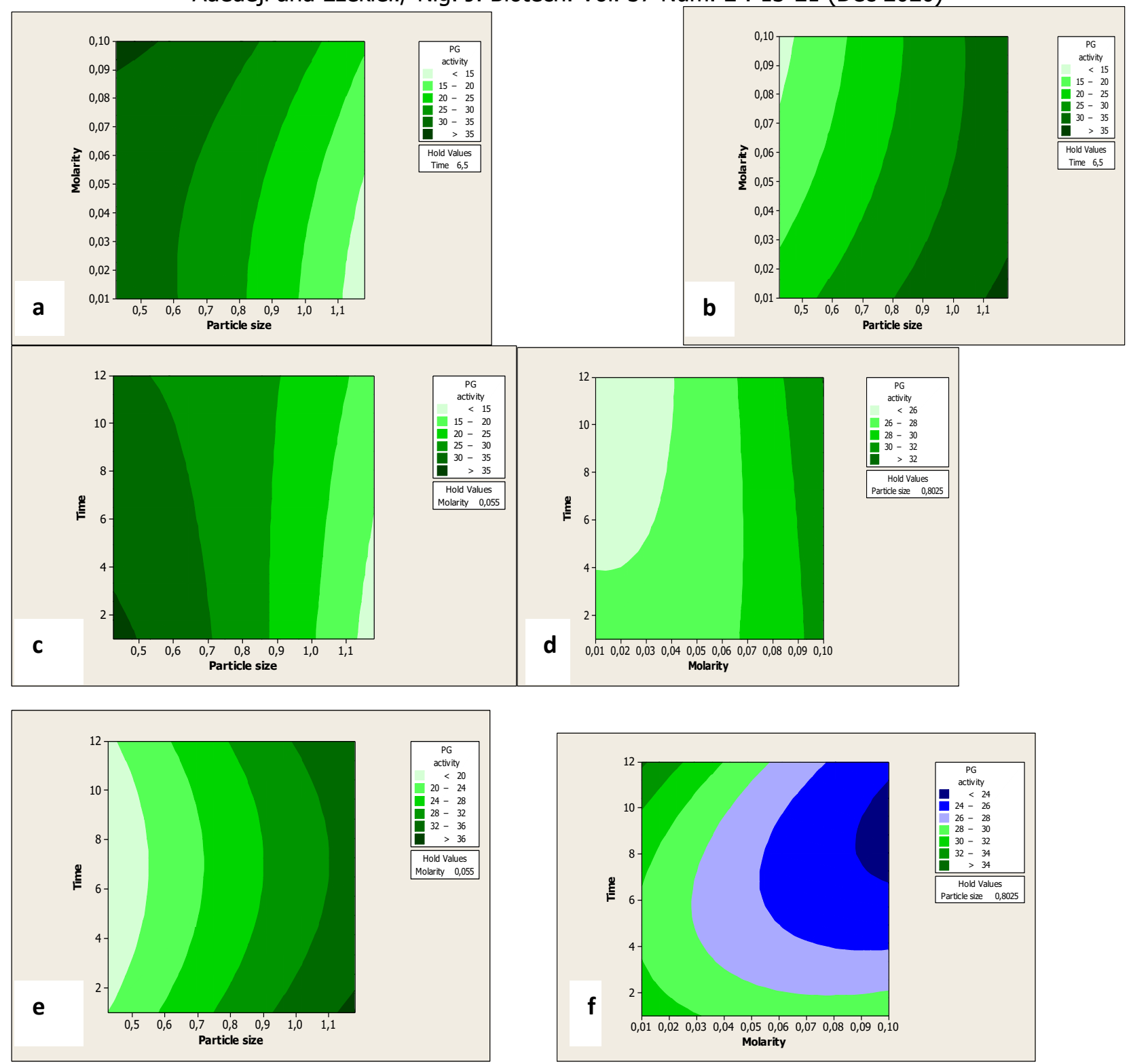

Figure 1. Effect of alkaline pretreatment condition on PG activity (a) effect of particle size and $\mathrm{NaOH}$ molarity on PG activity produced using pretreated orange peel, (b) effect of particle size and $\mathrm{NaOH}$ molarity on PG activity produced using pretreated plantain peel, (c) effect of particle size and time on PG activity produced using pretreated orange peel, (d) effect of particle size and time on PG activity produced using plantain peel, (e) effect of $\mathrm{NaOH}$ molarity and time on PG activity produced using orange peel, (f) effect of $\mathrm{NaOH}$ molarity and time on PG activity produced using plantain peel.

\section{References}

Adedeji, O.E. and Ezekiel, O.O. (2019). Pretreatment of selected peels for polygalacturonase production by Aspergillus awamori CICC 2040: Purification and application in mango juice extraction. Bioresour. Technol. Rep. 7: 100306.

Akinpelu, E.K., Ntwampe, S.K.O., Mekuto, L. and Tombo, E.F.I. (2016). Optimizing the bioremediation of free cyanide containing wastewater by Fusarium oxysporum grown on 
Adedeji and Ezekiel./ Nig. J. Biotech. Vol. 37 Num. 2 : 13-21 (Dec 2020)

beetroot waste using response surface methodology. Proceedings of the World Congress on Engineering and Computer Science, October 19-21, 2016, San Francisco, USA.

Anuradha, K., Padma, P.N., Venkateshwar, S. and Reddy, G. 2010. Fungi isolates from natural pectic substrates for polygalacturonase and multi enzyme production. Indian J. Microbiol. 50: 339344.

Anuradha, K., Padma, P.N., Venkateshwar, S. and Reddy, G. (2014). Selection of nutrients for polygalacturonase production by Aspergillus awamori MTCC 9166 using Placket-Burman design. Indian J. Biotechnol. 13: 502-507.

Castillo-Israel, K.A.T., Baguio, S.F., Diasanta, M.D.B., Lizardo, R.C.M., Dizon, E.I. and Mejico, M.I.F. (2015). Extraction and characterization of pectin from Saba banana [Musa 'saba'(Musa acuminata x Musa balbisiana)] peel wastes: A preliminary study. Int. Food Res. J. 22(1): 190195.

Dey, T.B., Adak, S., Bhattacharya, P. and Banerjee, R. (2014). Purification of polygalacturonase from Aspergillus awamori Nakazawa MTCC 6652 and its application in apple juice clarification. LWT - Food Sci. Technol. 59: 591-595.

El-Shishtawy, R.M., Mohamed, S.A., Asiri, A.M., Gomaa, A.M., Ibrahim, I.H. and Al-Talhi, H.A. (2015). Saccharification and hydrolytic enzyme production of alkali pretreated wheat bran by Trichoderma virens under solid state fermentation. BMC Biotechnol. 15: 37-50.

Ezekiel, O.O. and Aworh, O.C. (2018).

Simultaneous saccharification and cultivation of Candida utilis on cassava peel. Innov. Food Sci. Emerg. Technol. 49:184-191.

Han, L., Feng, J., Zhang, S., Ma, Z., Wang, Y. and Zhang, X. (2012). Alkali pretreatment of wheat straw and its enzymatic hydrolysis. Braz. J. Microbiol. 43: 53-61.

Heerd, D., Yegin, S., Tari, C. and FernandezLahore, M. (2012). Pectinase enzymecomplex production by Aspergillus spp. in solid-state fermentation: a comparative study. Food Bioprod. Process. 90: 102-110.

Heerd, D., Diercks-Horn, S. and FernándezLahore, M. (2014). Efficient polygalacturonase production from agricultural and agro-industrial residues by solid-state culture of Aspergillus sojae under optimized conditions. SpringerPlus 3:742754.

Ju, X., Engelhard, M. and Zhang, X., 2013. An advanced understanding of the specific effects of xylan and surface lignin contents on enzymatic hydrolysis of lignocellulosic biomass. Bioresour. Technol. 132(3): 137-145.

Khatri, B.P., Bhattarai, T., Shrestha, S. and Maharjan, J. (2015). Alkaline thermostable pectinase enzyme from Aspergillus niger strain MCAS2 isolated from Manaslu Conservation Area, Gorkha, Nepal. SpringerPlus 4: 488-496.

Lai, C., Tang, S., Yang, B., Gao, Z., Li, X. and Yong, Q. (2017). Enhanced enzymatic saccharification of corn stover by in-situ modification of lignin with poly (ethylene glycol) ether during low temperature alkali pretreatment. Bioresour. Technol. 244: 92-99.

Li, P., Xia, J., Shan, Y., Nie, Z. and Wang, F. (2015). Effect of surfactant and microwaveassisted pretreatment on orange peel on extracellular enzymes production by Aspergillus japonicas PJ10. Appl. Biochem. Biotechnol. 176:758-771.

Low, J.C., Halis, R., Shah, U.K., Tahir, P., Abood, F., Tukimin, T., Idris, M.D., Lanika, L. and Razali, N. 2015. Enhancing enzymatic digestibility of alkaline pretreated banana pseudostem for sugar production. Bioresour. 10: 1213-1223.

Maeda, R.N., Serpa, V.I., Rocha, V.A.L., Mesquita, R.A.A., Anna, L.M.M.S., de Castro, A.M., Driemeier, C.E., Pereira, N. and Polikarpov, I. (2011). Enzymatic hydrolysis of pretreated sugar cane bagasse using Penicillium funiculosum and Trichoderma harzianum cellulases. Process Biochem. 46: 1196-1201.

Obi, F.O., Ugwuishiwu, B.O. and Nwakaire, J.N. (2016). Agricultural waste concept, generation, utilization and management. Nig. J. Technol. 35(4): $957-964$.

Padma, P.N., Anuradha, K., Nagaraju, B., Kumar, V.S. and Reddy, G. (2012). Use of pectin rich fruit wastes for polygalacturonase production by Aspergillus awamori MTCC 9166 in solid state fermentation. Bioprocess. Biotech. 2(2): 116-118. 
Adedeji and Ezekiel./ Nig. J. Biotech. Vol. 37 Num. 2 : 13-21 (Dec 2020)

Pandey, A.K. and Negi, S. (2015). Impact of surfactant assisted acid and alkali pretreatment on lignocellulosic structure of pine foliage and optimization of its saccharification parameters using response surface methodology. Bioresour. Technol. 192: 115-125.

Ptichkina, N.M., Markinaa, O.A. and Rumyantseva, O.A. (2008). Pectin extraction from pumpkin with the aid of microbial enzymes. Food Hydrocoll. 22: 192-195.

Rahnama, N., Mamat, S., Shah, U.K., Ling, F.H., Abdulrahman, N.A. and Ariff, A.B. (2013). Effect of alkali pretreatment of rice straw on cellulose and xylanase production by local Trichoderma harzianum SNRS under solid state fermentation. Bioresour. 8(2): 2881-2896.

Sahare, P., Singh, R., Laxman, R.S. and Rao, M. (2012). Effect of alkali pretreatment on the structural properties and enzymatic hydrolysis of corn cob. Appl. Biochem. Biotechnol. 168: 1806-1819.

Salihu, A., Abbas, O., Sallau, A.B. and Alam, Z. (2015). Agricultural residues for cellulolytic enzyme production by Aspergillus niger: effect of pretreatment. 3 Biotech 5: 1101-1106.

Santos, A.L.F. Kawase, K.Y.F. and Coelho, G.L.V. (2011). Enzymatic saccharification of lignocellulosic materials after treatment with supercritical carbon dioxide. J. Supercrit. Fluid 56: 277-282.

Tapre, A.R. and Jain, R.K. (2014). Pectinases: enzymes for fruit processing industry. Int. Food Res. J. 21(2): 447-453.

Wadhwa, M., Bakshi, M.P.S. and Makkar, H.P.S. (2015). Wastes to worth: value added products from fruit and vegetable wastes. CAB Rev. 10: 4368.

Wu, F., Jin, Y., Xu, X. and Yang, N. (2017). Electrofluidic pretreatment for enhancing essential oil extraction from citrus fruit peel waste. J. Clean. Prod. 159:85-94

Yang, M., Wang, J., Hou, X., Wu, J., Fan, X., Jiang, F. and Zhang, J. (2017). Exploring surface characterization and electrostatic property of Hybrid Pennisetum during alkaline sulfite pretreatment for enhanced enzymatic hydrolysability. Bioresour. Technol. 244: 1166117.
Yu, H., Li, X., Zhang, W., Sun, D., Jiang, J. and Liu, Z., 2015. Hydrophilic pretreatment of furfural residues to improve enzymatic hydrolysis. Cellul. 22.3:1675-1686. 